\title{
Use of Mixed Self-Assembled Monolayers in a Study of the E ffect of the Microenvironment on Immobilized Glucose Oxidase
}

\author{
A. J orge Guiomar,* J ames T. Guthrie, and Stephen D. Evans \\ Centre for Self-Organising Molecular Systems, University of Leeds, Leeds LS2 9J T, UK
}

Received August 4, 1998. In Final Form: November 30, 1998

\begin{abstract}
Mixed self-assembled monolayers (SAMs) composed of a medium length, reactive, n-organothiol (11mercaptoundecanoic acid) and a short length, unreactive, hydrophobic n-alkylthiol (7-heptanethiol) chemisorbed onto evaporated gold surfaces, were used to study the effect of the microenvironment on the structureand activity of immobilized glucose oxidase (GOX). The mixed SAM s werecharacterized by X-ray photoelectron spectroscopy, contact angle measurements, and cyclic voltammetry. The derivatization of the SAMs for the coval ent attachment and the immobilized enzyme were studied by X-ray photoelectron spectroscopy. Quantitative analysis of the amide I band of the infrared spectra of GOX immobilized onto surfaces at the two attainable extremes of the hydrophilicity range available to us indicated that the percentage of $\beta$ sheet increased with increasing hydrophilicity of the microenvironment. Thespecificactivity of GOX was higher when the enzyme was immobilized onto the hydrophobic microenvironment.
\end{abstract}

\section{Introduction}

In the development of enzyme-based biosensors, the immobilization of the enzyme molecules by attachment to a surface has been widely used. ${ }^{1}$ The catalytic behavior of an immobilized enzyme is generally altered upon immobilization, because of (i) effects of the surface on the mass transport of the enzyme substrate and the reaction products $^{2}$ and (ii) alteration of theenzyme's conformation. ${ }^{3}$ A correlation between the character of the microenvironment into which theenzymeis placed upon immobilization and its resulting conformation and kinetic properties has always been desired.

Despitetheimportance of theimmobilization of glucose oxidase (GOX), an enzyme much used in electrochemical biosensors for thequantification of glucosein medical and industrial situations, ${ }^{4}$ few studies have been concerned with the conformational analysis of immobilized GOX. An ellipsometry study of GOX physisorbed onto gold showed that the thickness of the enzymelayer was below theenzyme's molecular dimensions, indicating unfol ding. ${ }^{5}$ A study of the amide I and amide II FTIR bands of GOX coval ently attached reveal ed that conformational changes did not occur upon immobilization. ${ }^{6}$ In addition, studies employing scanning probemicroscopes haverevealed that GOX molecules form clusters when physisorbed or covalently attached onto electrode surfaces ${ }^{7}$ and have allowed the visualization of the native and unfolded structures of physisorbed GOX. ${ }^{8}$

\footnotetext{
* To whom the correspondence should be addressed. Departamento de Bioquímica, Faculdade de Ciências e Tecnologia, Universidade de Coimbra, Apartado 3126, 3000 Coimbra, Portugal. E-mail: aguiomar@cygnus.ci.uc.pt.

(1) Scouten, W. H.; Luong, J . H. T.; Brown, R. S. Trends Biotechnol. 1995, 13, 178.

(2) Goldstein, L. Methods E nzymol . 1976, 44, 397. Clark, D. S. Trends Biotechnol. 1994, 12, 439.

(3) Pye, E. K.; Chance, B. Methods Enzymol . 1976, 44, 357. Buchholz, K.; Klein, J. Methods Enzymol. 1987, 135, 3.

(4) Wilson, R.; Turner, A. P. F. Biosens. Bioelectron. 1992, 7, 165.

(5) Szucs, A.; Hitchens, G. D.; Bockris, J . O' M. J . Electrochem. Soc. 1989, 136, 3748 35.

(6) Taga, K.; Kellner, R.; Kainz, U.; Sleytr, U. Anal. Chem. 1994, 66,

(7) Taga, K.; Schwarzbach, D.; Stingeder, G.; Grasserbauer, M.; Kellner, R. Anal. Chem. 1993, 65, 2288. Cullen, D. C.; Lowe, C. R. J.
} Colloid Interface Sci. 1994, 166, 102.
In many electrochemical biosensors, the surface onto which the enzyme is to be immobilized is a metal. When direct attachment to the el ectrode is required, the metal must bemodified with an organicoverlayer that possesses functional groups. This can be achieved by modification with organic monolayers or multilayers, employing the self-assembly or the Langmuir-Blodgett/LangmuirSchaefer methods. ${ }^{9}$ Such organicfilms bring thefollowing advantages: (i) extremely reduced thickness, (ii) surface groups optimally positioned for reaction, (iii) control in the degree of order and density of reactive groups, and (iv) reduction of non-Faradaic currents. In this work, selfassembled monol ayers (SAMs) of organothiols were used to modify gold surfaces. These monolayers are formed by the spontaneous chemisorption of organothiols on gold surfaces. ${ }^{9-15}$

Mixtures of organothiols having different terminal groups have been used by our group and others to prepare mixed SAM s. ${ }^{12,16-18}$ These systems can be used as model surfaces to study the effect of the hydrophilicity/hydrophobicity of the microenvironment on an immobilized enzyme. SAMs of $n$-organothiol s on gol d haveal ready been adopted as model surfaces in quantitative and conformational studies of protein physisorption. ${ }^{19}$ We have employed here both single-component SAMs and mixed SAMs composed of a mixture of a medium length,

(8) Chi, Q.; Zhang, J .; Dong, S.; Wang, E. J . Chem. Soc., Faraday Trans. 1994, 90, 2057.

(9) UIman, A. An Introduction to UItrathin Organic Films - From Langmuir-Blodgett toSelf-Assembly; AcademicPress: New York, 1991.

(10) Nuzzo, R. G.; Allara, D. L. J . Am. Chem. Soc. 1983, 105, 4481.

(11) Bain, C. D.; Whitesides, G. M. J . Am. Chem. Soc. 1989, 111 7164.

(12) Bain, C. D.; Evall, J .; Whitesides, G. M.J . Am. Chem. Soc. 1989, $111,7155$.

(13) Bain, C. D.; Troughton, E. B.; Tao, Y.-T.; Evall, J .; Whitesides, G. M.; Nuzzo, R. G. J . Am. Chem. Soc. 1989, 111, 321.

(14) Nuzzo, R. G.; Dubois, L. H.; Allara, D. L. J . Am. Chem. Soc. 1990, 112,558

(15) Dubois, L. H.; Nuzzo, R. G. Annu. Rev. Phys. Chem. 1992, 43 , 437.

(16) Evans, S. D.; Sharma, R.; UIman, A. Langmuir 1991, 7, 156.

(17) UIman, A.; Evans, S. D.; Shnidman, Y.; Sharma, R.; Eilers, J . E.; Chang, J . C. J . Am. Chem. Soc. 1991, 113, 1499.

(18) Laibinis, P. E.; Nuzzo, R. G.; Whitesides, G. M. J . Phys. Chem 1992, 96, 5097.

(19) Mrksich, M.; Whitesides, G. M. Annu. Rev. Biophys. Biomol. Struct. 1996, 25, 55 . 

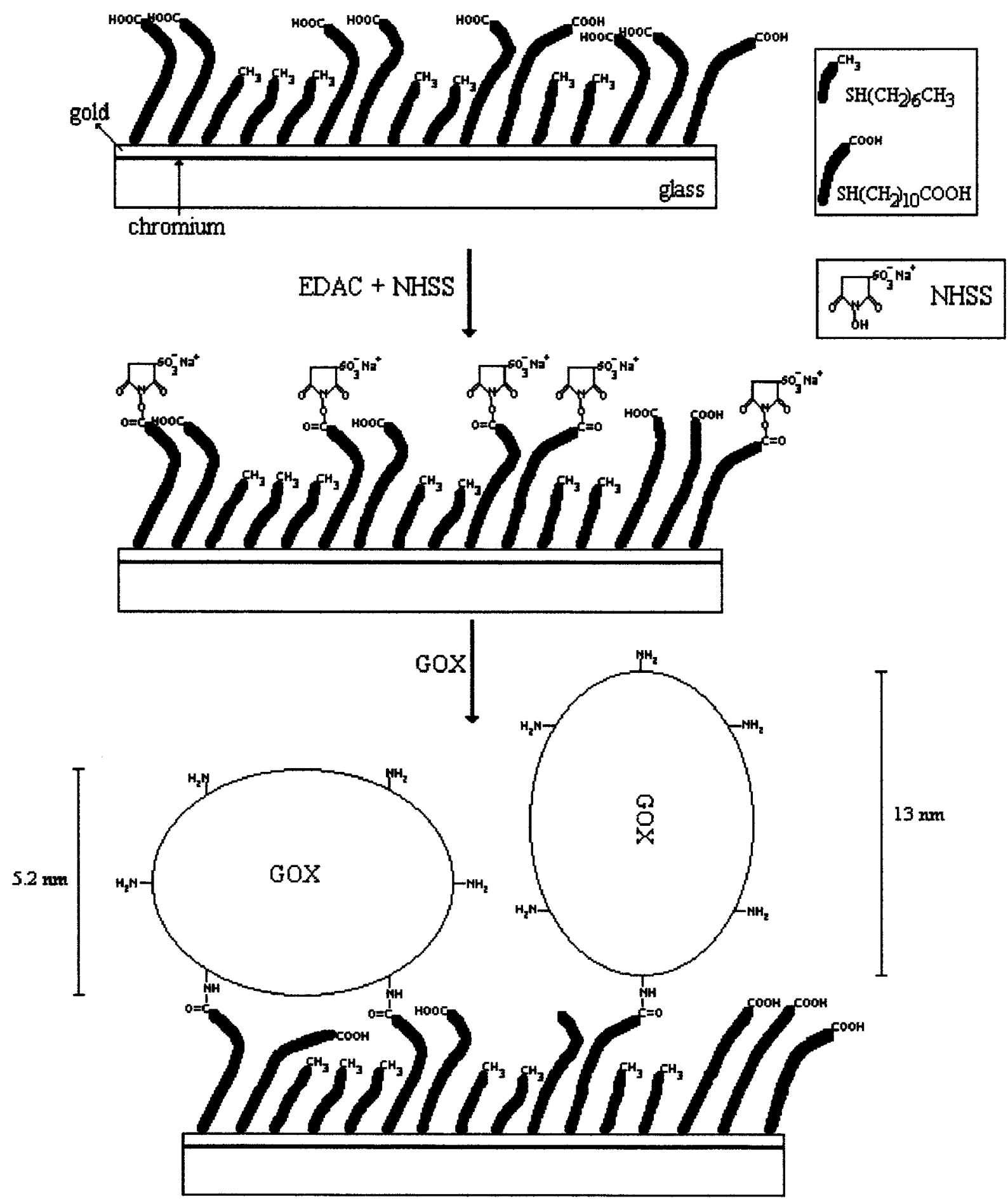

Figure 1. Schematic representation of the immobilization of GOX by covalent attachment to a mixed MUA/C7 SAM on a gold surface (not drawn to scale). GOX is represented attached in the two limiting orientations.

carboxylic acid functionalized derivative (11-mercaptoundecanoic acid, MUA) and a short length, methyl functional ized derivative(7-heptanethiol, C7). Themixture of these two molecules allowed the creation of a range of surfaces of varying hydrophilicity, providing carboxylic groups that are in a disordered stateand that are exposed at the surface, hence being optimally located for reaction ${ }^{11,18}$ (Figure 1). As the "inner" part of the SAM is thin and poorly ordered, it allows facile el ectron transfer to the underlying gold layer (used, for instance, as an electrode in electrochemical biosensors).

SAM s of organothiols on gold have previously been used in the preparation of el ectrochemical biosensors with GOX.
The approaches taken to the preparation of this type of biosensor can bedivided accor ding to the fashion in which the enzyme immobilization was achieved, i.e., employing immobilization by adsorption (with ${ }^{20}$ or without ${ }^{21-23}$ subsequent cross-linking) or employing immobilization by covalent attachment. ${ }^{24-27}$ Two novel approaches were

(20) Creager, S.; Olsen, K. G. Anal. Chim. Acta 1995, 307, 277.

(21) Hodak, J .; Etchenique, R.; Calvo, E.J .; Singhal, K.; Bartlett, P. N. Langmuir 1997, 13, 2708. 251.

(22) Mizutani, F.; Sato, Y.; Yabuki, S.; Hirata, Y. Chem. Lett. 1996,

(23) He, P.; Ye, J .; Fang, Y.; Ansai, J .; Osa, T. Talanta 1997, 44, 885.

(24) J iang, L.; McNeil, C. J .; Cooper, J . M. J . Chem. Soc., Chem. Commun. 1995, 1293. 
direct chemisorption of GOX onto gold via its two surface disulfide bridges ${ }^{28}$ and electrical "wiring" of GOX via specific binding of apo-GOX to flavine adenine dinucleotide-terminated SAMs. ${ }^{29}$

In this study, GOX was immobilized ontoSAMs in two different ways: (i) physisorption onto the SAMs, and (ii) covalent attachment tothecarboxylic groups of theSAMs. The covalent attachment method employed a watersoluble $\mathrm{N}$-hydroxysuccinimide derivative ( $\mathrm{N}$-hydroxysulfosuccinimide, NHSS), assisted by a water-soluble Nsubstituted carbodiimide \{1-ethyl-3-[3-(dimethylamino)propyl ]carbodiimide, EDAC\}, resulting in the formation of mainly amide bonds between enzyme and SAM molecules (Figure 1). ${ }^{24,30}$ To prevent intermol ecular enzyme cross-linking and the consequent immobilization of crosslinked enzyme networks, the derivatization step was separated from the enzyme-coupling step. In this way, the microenvironment of a given immobilized enzyme molecule was determined by the immobilization matrix, rather than by other enzymemolecules of the cross-linked enzyme networks. Conformational information was obtained from analysis of the infrared amide I band. The activity of the immobilized enzyme was detected by cyclic voltammetry, using a ferrocene derivative as a redox mediator.

\section{Methods}

Preparation of Self-Assembled Monolayers of Organothiols on Gold. Gold-coated glass slides were prepared by resistiveevaporation of gol d ontomicroscopegl ass sl ides (Chance Propper Ltd., Warley, UK), using an Edwards Auto 306 Turbo vacuum coater (Edwards High Vacuum Int., Warley, UK). The glass slides were cleaned by sonication in a dilute Decon 90 or Deconex (Decon Laboratories Ltd., Sussex, UK) aqueous sol ution, followed by a thorough rinse with Milli Q Plus water (Millipore Corp., Bedford, USA) and, finally, theslides wereblown dry with nitrogen. The slides wer further cleaned by either etching with an argon plasma (Plasma Preen I plasma cleaner, Plasmatic Systems Inc., North Brunswick, USA) or etching for $30 \mathrm{~min}$ in a freshly prepared, hot "piranha solution" [1:4 hydrogen peroxide (30\%)/concentrated sulfuric acid]. ${ }^{31}$ I $\mathrm{n}$ both cases, theslides were subsequently rinsed with Milli Q Plus water (after which they were completely wetted by water) and blown dry with nitrogen. A chromium adhesion layer $1.0 \mathrm{~nm}$ thick (the thickness being monitored with a Edwards FTM5 quartz oscillator) was first deposited on the glass slides by evaporation of chromium from a chromium-plated tungsten wire (E dwards High Vacuum Int.), at an evaporation rate of $0.1 \mathrm{~nm} / \mathrm{s}$ and a pressure of $\sim 1 \times 10^{-6}$ mbar. Gold (99.999\%, Advent Research Materials, Ltd., Halesworth, UK) was evaporated at a rate of $0.2-0.3 \mathrm{~nm} / \mathrm{s}$, to a thickness of $200 \mathrm{~nm}$.

The gold surfaces were cleaned immediately before use by either a very mild plasma etching or, when preparing electrodes for the electrochemical studies, etching for $5 \mathrm{~min}$ in freshly prepared, hot "piranha solution". ${ }^{31}$ In both cases, a rinsing step with Milli Q Plus water followed. The gold-coated slides were then immersed in solutions of C7 (98\%, Fluka, Poole, UK), MUA ( $95 \%$, Aldrich Chemical Co., Poole, UK), or mixtures of thesetwo compounds in absol uteethanol (BDH, Poole, UK or Merck, Poole,

(25) Kajiya, Y.; Okamoto, T.; Yoneyama, H. Chem. Lett. 1993, 2107

(26) Willner, I.; Riklin, A.; Shhoham, B.; Rivenzon, D.; Katz, E. Adv. Mater. 1993, 5, 912

(27) Rubin, S.; Chow, J . T.; Ferraris, J . P.; Zawodzinski, T. A., J r. Langmuir 1996, 12, 363.

(28) Alvarez-I caza, M.; Kalisz, H. M.; Hecht, H. J .; Aumann, K.-D.; Schomburg, D.; Schmid, R. D. Biosens. Bioel ectron. 1995, 10, 735.

(29) Willner, I.; Heleg-Shabtai, V.; Blonder, R.; Bückmann, A. F .; Heller, A. J . Am. Chem. Soc. 1996, 118, 10321.

(30) Staros, J . V.; Wright, R. W.; Swingle, D. M. Anal. Biochem. 1986 156, 220. Sehgal, D.; Vijay, I. K. Anal. Biochem. 1994, 218, 87. Frey, B. L.; Corn, R. M. Anal. Chem. 1996, 68, 3187.

(31) CAUTION! "Piranha solution" is a very oxidizing solution that reacts violently with most organic materials; it must be handled with extreme care.
UK). The total concentration of organothiols in every solution was $1 \mathrm{mM}$. After an immersion time of $1 \mathrm{~h}$, the slides were thoroughly rinsed with absolute ethanol and blown dry with nitrogen.

I mmobilization of Glucose Oxidase. GOX (265 units/mg, Biozyme, Gwent, UK, donated by MediSense, Abingdon, UK) was immobilized onto the SAM-modified, gold-coated slides, by either simple physisorption or coval ent attachment. I mmobilization by physisorption was achieved by immersing the slides overnight in a $2 \mathrm{mg} / \mathrm{cm}^{3}$ stirred solution of GOX in $0.1 \mathrm{M}$ sodium phosphate buffer at $\mathrm{pH} 7.0$ and at room temperature. The slides were then thoroughly rinsed with the following sequence of liquids: Milli Q Plus water, pH 7.0 phosphate buffer solution, $1 \mathrm{M} \mathrm{NaCl}$, and $\mathrm{pH} 7.0$ phosphate buffer solution again.

For the covalent immobilization, theslides modified with SAMs containing terminal carboxylic groups weretreated with a stirred $0.1 \mathrm{M}$ sodium phosphate buffer solution at $\mathrm{pH} 7.3$, containing NHSS ( $5 \mathrm{mM}$, Pierce, Rockford, USA) and EDAC ( $20 \mathrm{mM}$, Aldrich) at room temperature. After a reaction time of $3 \mathrm{~h}$, they were rinsed with the phosphate buffer and immediately placed in a stirred $2 \mathrm{mg} / \mathrm{cm}^{3} \mathrm{GOX}$ solution in $0.1 \mathrm{M}$ sodium phosphatebuffer at $\mathrm{pH}$ 6.3. This step was allowed to proceed overnight at room temperature. The slides were then thoroughly rinsed with the following sequence of liquids: $\mathrm{pH} 6.3$ buffer solution, $1 \mathrm{M} \mathrm{NaCl}$, Milli Q Plus water, and pH 7.0 sodium phosphatebuffer solution.

Characterization of the Monolayers. Wettability by Water. Wettability of the SAMs by water was evaluated by measuring advancing contact angles $\left(\theta_{\mathrm{a}}\right)$ with captive droplets of Milli Q Plus water. I mages of the droplets were obtained with the aid of a video camera and analyzed with image analysis software. The contact angle measurement apparatus and procedure are described elsewhere. ${ }^{32}$

FTIR (Fourier Transform I nfrared) Spectroscopy. The FTIRATR (Attenuated Total Reflectance) spectra of GOX immobilized onto SAMs were recorded with a Bruker IFS 48 FTIR spectrometer and acquired with a variable angle ATR accessory for liquid samples (Graseby Specac, Orpington, UK), containing a ZnSe parallelogram of dimensions $64.2 \times 12 \times 4.2 \mathrm{~mm}$, with a $45^{\circ}$ chamfer. The infrared beam was incident on the face of the crystal at $45^{\circ}$, and internally reflected 14 times. Spectra were acquired in the absence of a polarizer, at a resolution of either 2 or $4 \mathrm{~cm}^{-1}$, with 2000 scans being co-added. For this study, SAM s were prepared onto both faces of a gold-coated ZnSecrystal, in a manner similar to that described above for the gold-coated glass slides. Themain exceptions were (i) nochromium adhesion layer was used, and (ii) the thickness of the gold layer was 20 $\mathrm{nm}$, so that enough infrared radiation could pass through it.

For the acquisition of the spectrum of immobilized GOX, the single-channel background spectrum of the dry SAM-coated crystal was first acquired in air, after adequate purging with dry air. This spectrum was used as the background spectrum for all the spectra subsequently acquired. The immobilization of GOX onto SAM-coated ATR crystals was performed analogously to the physisorption or covalent attachment onto SAMs on slides. It was carried out in the ATR cell, circulating the liquids with the aid of a peristaltic pump. Spectra were acquired with quiescent pH 7.0 phosphate buffer in the cell, before the immobilization of the enzyme, and after the rinsing step that followed theimmobilization step. Spectra of GOX in solution (48 $\mathrm{mg} / \mathrm{cm}^{3}$ in $0.1 \mathrm{M}$ sodium phosphatebuffer at $\mathrm{pH} 7.0$ ) wereacquired with a transmission cell for liquid samples (calcium fluoride windows separated by a $6 \mu \mathrm{m}$ Mylar spacer).

Spectra of the enzyme (immobilized or in solution) were obtained by subtracting the spectrum of the buffer solution from that of the enzyme (immobilized or in solution) in the presence of buffer, using the double-subtraction method of Dong and coworkers. ${ }^{33}$ The enzyme spectra were normalized to a waterbending modeintensity of 0.7 units of absorbanceat $1640 \mathrm{~cm}^{-1.34}$ This was achieved by multiplying the buffer-subtracted enzyme

(32) Guiomar, A.J .; Evans, S. D.; Guthrie, J . T. Supramol . Sci . 1997 4,279 .

(33) Dong, A.; Caughey, W. S. Methods Enzymol. 1994, 232, 139.

(34) Fink, D. J .; Gendreau, R. M. Anal. Biochem. 1984, 139, 140. 
spectra by a normalization factor $\mathrm{N}$ that was computed as

$$
N=\frac{0.7}{I_{1640}^{E+B}-I_{1640}^{E}}
$$

where $\mathrm{I}_{1640}^{\mathrm{E}+\mathrm{B}}$ is the intensity at $1640 \mathrm{~cm}^{-1}$ of the total absorbance spectrum (enzyme in buffer) and $\mathrm{I}_{1640}^{\mathrm{E}}$ is the equival ent intensity of the absorbance spectrum of the enzyme (after subtraction of the absorbance spectrum of the buffer).

Resolution enhancement of the amidel band by curve-fitting was accompl ished by empl oying a method based on that devel oped by Byler and Susi, ${ }^{35}$ using Gaussian band shapes with a starting fwhh (full-width at half-height) of $8 \mathrm{~cm}^{-1}$. The number of single bands contained in the amide I envel ope and their start position were obtained from smoothed second derivative spectra (Savitsky-Golay smoothing) and confirmed by Fourier self-deconvolution (FSD). To avoid divergence of the iteration and very long iteration times, Byler and Susi's approach was altered by including two iteration cycles of a local least-squares iteration before the curve-fitting routine. Additionally, as recommended by others, ${ }^{36}$ the original amide I band, rather than the F ourier deconvoluted band, was curve-fitted. The relative area of the singlebands under theamidel envel opewas used as an estimate of the percentage of the el ements of secondary structure ( $\alpha$ helix, $\beta$ sheet, turns, and unordered segments) in the enzyme structure. ${ }^{35}$

X-ray Photoel ectron Spectroscopy (XPS). TheSAM s employed in the XPS studies were formed on silicon squares of approximately $1 \mathrm{~cm}^{2}$, cut from $\mathrm{Si}(100)$ wafers with a thickness of $0.56 \mathrm{~mm}$ (Advent Research Materials, Ltd., Halesworth, UK). Silicon slides were used instead of glass slides in order to minimize charging effects during spectra acquisition. Self-assembly was carried out as described above for the SAM-coated glass slides. The samples were stored in air, in individual dosed plastic containers. The analyses took place 1-2 days after the samples wereprepared, empl oying a Scienta ESCA-300 XPS spectrometer (located at the Research Unit for Surfaces, Transforms and Interfaces, CLRC Laboratories, Daresbury, UK). TheX-ray source was a monochromated AI K $\alpha$ line $(1486.6 \mathrm{eV})$, operated at a power of $2.7 \mathrm{~kW}$ for SAMs and either 1.4 or $2.7 \mathrm{~kW}$ for SAMs with immobilized GOX. Takeoff angles (TOA) of $10^{\circ}$ and $90^{\circ}$ were employed. The analyzer was operated with a "pass energy" of $150 \mathrm{eV}$ and a slit width of $0.8 \mathrm{~mm}$. High-resolution scans were accumulated, resulting in acquisition times ranging from 0.8 $\min (2$ scans) to $3.3 \mathrm{~min}$ ( 5 scans) for the SAM s and $0.8 \mathrm{~min}(2$ scans) to 8 min (20 scans, for the weaker N 1s and S 2p signals) for the SAMs with immobilized GOX.

Resolution of overlapping peaks was accomplished by curve fitting the peak envelope with a sum of constrained Gaussian and L orentzian curves. Thecurve-fitting routinehad thefol lowing constraints: (i) thenumber of peaks and their respectivepositions were inferred from theshape of the peak, takinginto account the structure of the molecule being analyzed, (ii) the starting fwhh had a value of $1.0 \mathrm{~cm}^{-1}$, (iii) the Gaussian and Lorentzian curves were not allowed to be asymmetrical, and (iv) the fwhhs of the peaks were not al lowed to be higher than those found in spectra of polymers possessing the same functional groups. ${ }^{37}$ Peak areas were normalized by correcting for the different sensitivity factors and by dividing by the number of scans and the combined area of the $A u 4 f 3 / 2$ and $4 f 5 / 2$ signals. Atomic ratios were calculated from the total area of signals attributed to the relevant atoms, in normalized spectra. The XPS spectra were normalized by di vision by the number of scans and the combined area of the Au $4 \mathrm{f} 3 / 2$ and $A u 4 f 5 / 2$ signals.

Detection of I mmobilized Enzymatic Activity by Cyclic Voltammetry. The activity of GOX was evaluated by coupling the oxidation of glucose to the oxidation of hydroxymethylferrocene ( $\mathrm{HMF}$, donated by M ediSense) added to thetest solution, using cyclic voltammetry. ${ }^{38}$ The cyclic voltammetry setup was

(35) Byler, D. M.; Susi, H. Biopolymers 1986, 25, 469.

(36) Surewicz, W. K.; Mantsch, H. H. Biochim. Biophys. Acta 1988 $952,115$.

(37) Beamson, G.; Briggs, D. High-Resolution XPS of Organic Polymers. The Scienta ESCA300 Database; J ohn Wiley \& Sons: Chichester, 1992.

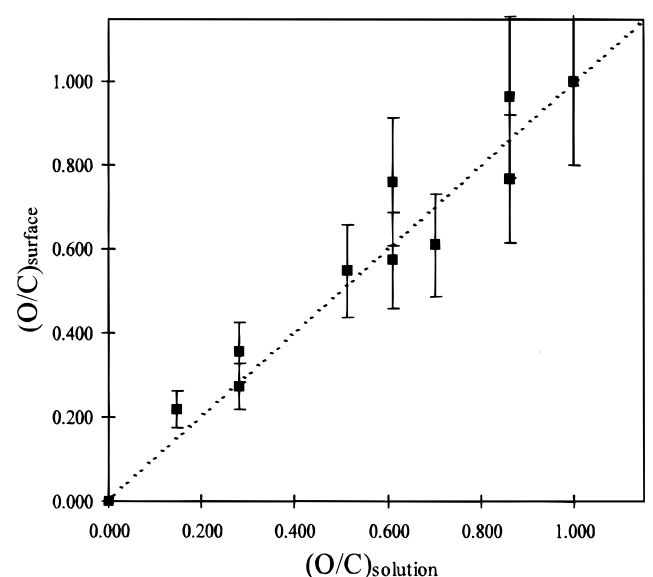

Figure 2. Plot of the normalized carbon-to-oxygen ratio on the surface of mixed MUA/C7 SAMs on gold (as determined by XPS) vs the sameratio in the solution from which self-assembly occurred (calculated). Each ratio was normalized by division by the ratio in a pure MUASAM. The line drawn shows the behavior expected if no preferential chemisorption of any of the molecules had occurred. Theer ror bars represent theestimated error involved in the determination.

composed of a scanning potentiostat (EG \& G PARC, model 362, Princeton Applied Research, Princeton, USA), interfaced to a 486 PC running Condecon 320 (EG \& G PARC) and a jacketed, single-compartment, three-el ectrode cell (M etrohm UK, Buckingham, UK), with provision for magneticstirring and for purging with water-saturated argon. The electrodes were made from metals of the highest purity available ( ohnson Matthey, Royston, UK and Advent Research Materials Ltd., Halesworth, UK) and were (i) a square platinum counter electrode, (ii) an $\mathrm{Ag} / \mathrm{AgCl}$ (saturated $\mathrm{KCl}$ ) reference electrode, and (iii) gold-coated glass slides, modified with the monolayers, as working electrodes. Cyclic voltammograms were acquired at $25^{\circ} \mathrm{C}$, at a scan rate of $1 \mathrm{mV} / \mathrm{s}$, in quiescent sodium phosphate/sodium chloride buffer solutions $\left(\mathrm{pH}=8.0 ; \mathrm{I}=0.1 \mathrm{M}\right.$; volume $\left.=15 \mathrm{~cm}^{3}\right)$, after purging with water-saturated argon for $15 \mathrm{~min}$. To prevent oxygen reentry into the solution, a blanket of water-saturated argon was kept abovethesolution during data acquisition. HMF c was added to a concentration of $50 \mu \mathrm{M}$, from $0.02 \mathrm{M}$ stock solutions in absolute ethanol. The cyclic voltammogram was repeated upon addition of glucose to a concentration of $50 \mathrm{mM}$, from a $3 \mathrm{M}$ glucosestock solution in theabove buffer (left overnight to ensure mutarotation). The standard deviation of $i_{\text {cat }}$ (the catalytic enhancement of the current) was estimated from 2 to 3 determinations with two electrodes.

\section{Results and Discussion}

Surface Composition of Mixed MUA/C7SAMs. XPS was used to determine the relative percentage of MUA and C7 in mixed SAMs. Figure 2 shows a plot of the normalized oxygen-to-carbon ratio $(\mathrm{O} / \mathrm{C})$ in the mixed MUA/C7SAMs (determined from theXPS spectra) versus the normalized $\mathrm{O} / \mathrm{C}$ ratio in the solution from which selfassembly occurred (calculated). The data points are scattered around the diagonal of the plot, indicating that neither MUA nor C7 was preferentially chemisorbed. Thus, the molar fraction of the two molecules in the solution was reproduced in the SAM.

Contact angle analysis showed that the mixed SAMs had a character ranging from highly hydrophilic (MUASAM) to hydrophobic (C7SAM). A plot of the cosine of the advancing contact angle against the XPS-determined composition of the SAM is given in Figure 3. Lines

(38) Bourdillon, C.; Demaille, C.; Moiroux, J .; Savéant, J .-M. J . Am. Chem. Soc. 1993, 115, 2.

(39) Cassie, A. B. D. Discuss. Faraday Soc. 1948, 3, 11 


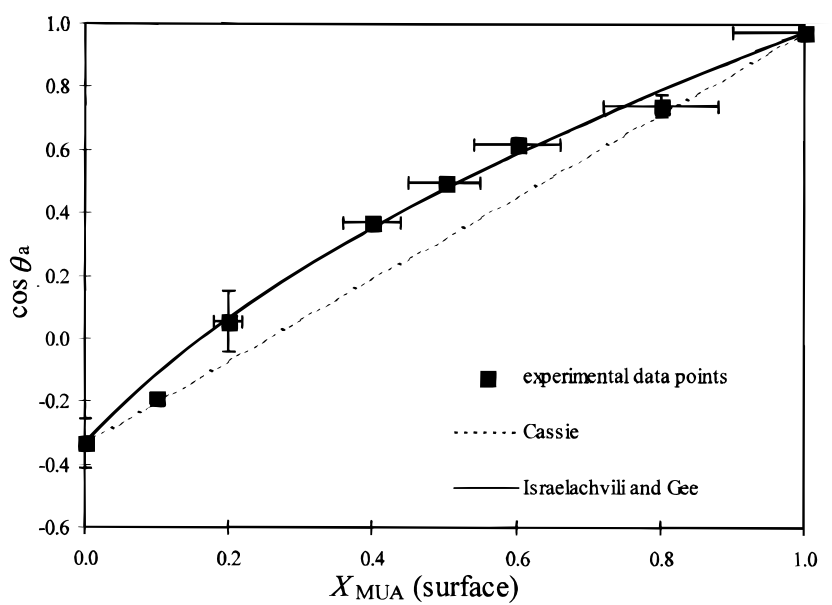

Figure 3. Variation of the advancing contact angle of water with the composition of the mixed SAMs. $\mathrm{X}_{\text {MUA }}$ is the molar fraction of MUA. The lines are plots of the expected behavior of theMUA/C 7 system according totheCassieequation ${ }^{39}$ (dotted line) and according tothel srael achvili and $\mathrm{Gee}^{40}$ equation (solid line). The vertical error bars in most of the data points have a length similar to the height of the data point marker.

representing both the Cassie $\mathrm{e}^{39}$ and the I sraelachvili and $\mathrm{Gee}^{40}$ equations, which rel ate the observed contact angle tothecomposition of thesurfacein the presence or absence of macroscopic phasesegregation, respectively, wereadded to the plot. The Israelachvili and Gee equation best fitted the experimental data, indicating the absence of macroscopic phase segregation. Data points in both extremes of the plot $\left(\mathrm{X}_{\mathrm{MUA}}=0.0,0.1,0.8\right.$, and 1.0$)$ were in agreement with both equations, indicating the possibility of the occurrence of macroscopic phase segregation when one component molecule dominates the composition of the mixed SAM.

Characterization of Mixed MUA/C7 SAMs by Cyclic Voltammetry. The oxidation/reduction of an el ectroactive species at evaporated gold el ectrodes modified with mixed SAMs was studied by cyclic voltammetry. Electrodes modified with MUASAM s showed background, non-F aradaic currents that wereconsi der ably lower than those of bare gold electrodes (Figure 4A). This decrease in the non-Faradaic current is a consequence of the increase in the electrical double-layer capacitance, caused by the presence of the SAM at the metal/electrolyte interface. Electrodes modi fied with mixed MUA/C7SAMs having a large molar fraction of MUA (0.6) showed background curves close to that of MUASAM-modified electrodes (curves not shown), showing that the access of ions and solvent molecules to the gold surface was mini mized. I n contrast, those modi fied with mixed MUA/ C7 SAMs having a small molar fraction of MUA showed curves close to that of bare gold and the formation of gold oxide (curves not shown), indicating that the approach of ions and solvent molecules to the gold surface occurred and that "defect sites" (probably disordered regions) exist in the SAM. C7SAM-modified electrodes were an intermediate case.

The effect of the MUASAM on the oxidation/reduction of HMFC is shown in Figure 4B. HMFc was used as the redox species because it can mediate electron transfer between oxidases such as GOX and an electrode. ${ }^{38}$ The oxidation and reduction of HMF c was little affected by the presence of the MUASAM on the gold surface. The electrodes modified with MUASAM showed voltammograms with reduced current densities and a slight positive

(40) Israelachvili, J . N.; Gee, M. L. Langmuir 1989, 5, 288.
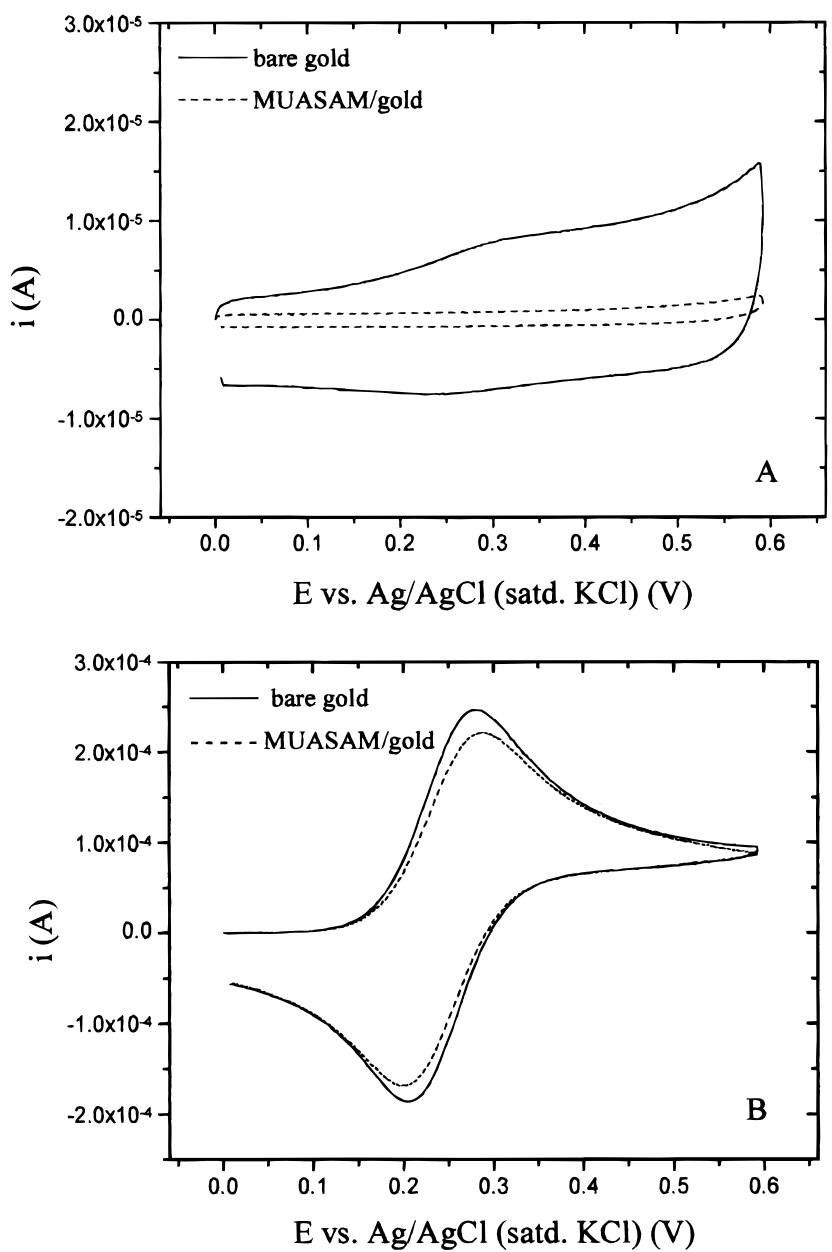

Figure4. Cyclic voltammograms of evaporated gol d electrodes before and after modification with a MUASAM (scan rate, 100 $\mathrm{mV} / \mathrm{s}$; electrode area, $2.2 \mathrm{~cm}^{2}$ ). Electrolyte: $0.01 \mathrm{M}$ sodium phosphate buffer at $\mathrm{pH} 7.0$, with $\mathrm{NaCl}(0.09 \mathrm{M})$. (A) Background currents. (B) Cyclic vol tammograms of $0.5 \mathrm{M}$ solutions of HMFC in the electrolyte.

shift in the peak potentials. The mixed MUA/C7 SAMs showed vol tammograms coincident with the voltammogram of HMF c for bare gold electrodes, and the C7SAM showed voltammograms with current densities interme diate between those of bare gold and those of MUASAM modified gold, with no significant shift in the redox potential of HMFc (curves not shown). Thus, electrodes modified with MUASAMs, C7SAMs and mixed MUA/C7 SAMs could carry out the oxidation of HMFC in a quasireversiblemode, al lowing its useas a redox mediator.

For the oxidation of an el ectroactive species by the gold layer underlying a SAM, three possible paths can be consider ed: ${ }^{41}$ (i) access of the el ectroactive species to the gold layer through "pinholes" in the SAM, either closely or widely spaced; (ii) access tothegol d layer via membrane type permeation through the SAM; and (iii) transfer of

(41) Porter, M. D.; Bright, T. B.; Allara, D. L.; Chidsey, C. E. D. J . Am. Chem. Soc. 1987, 109, 3559.

(42) F urther support came from the observation that oxidation of HMF cat theseel ectrodes was quasireversible, indicating theoccurrence of a mechanism controlled by linear diffusion. This quasireversibility was characterized by (i) peak currents linearly dependent on the square root of the scan rate (for scan rates between 100 and $1 \mathrm{mV} / \mathrm{s}$ ); (ii) peak potentials nearly independent of the scan rate; (iii) peak separations slightly above $59 \mathrm{mV}$, being higher for single-component SAMs (76 mV for the MUASAM and $74 \mathrm{mV}$ for the C7SAM) than for the mixed SAM (64 mV for the mixed MUA/C 7 SAM with $\mathrm{X}_{M \cup A}=0.6$ and $66 \mathrm{mV}$ for the mixed MUA/C 7SAM with $X_{M U A}=0.2$ ); and (iv) ratio of anodictocathodic current close to unity. 
A
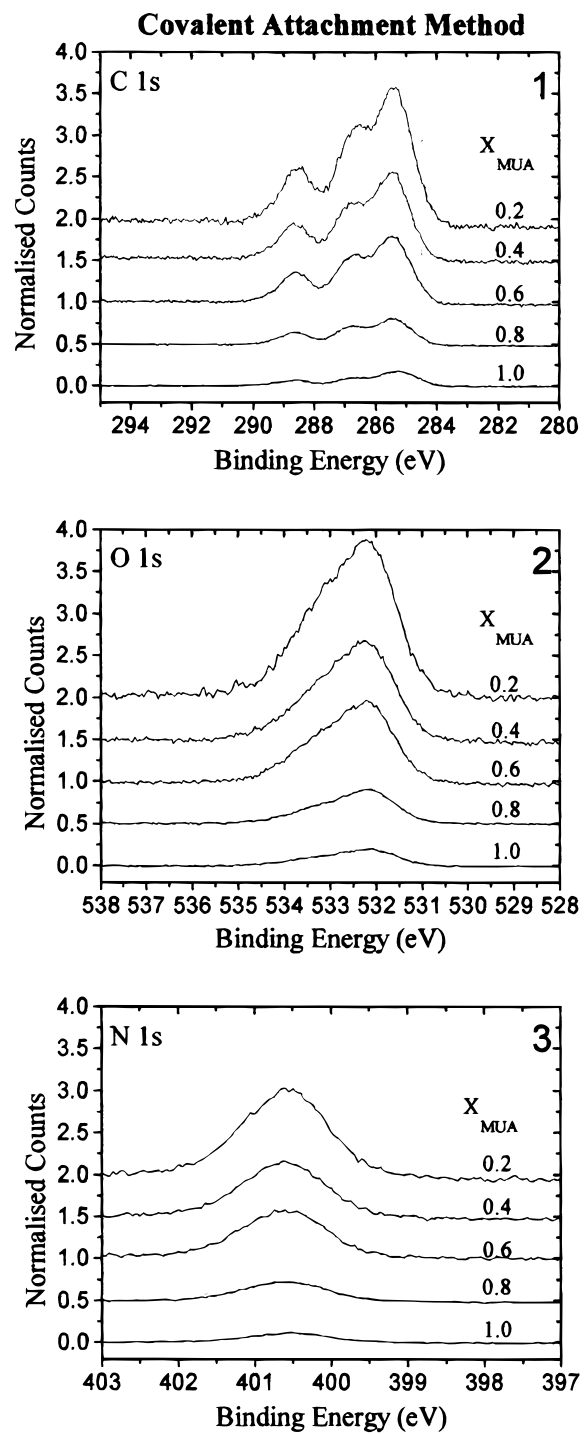

B
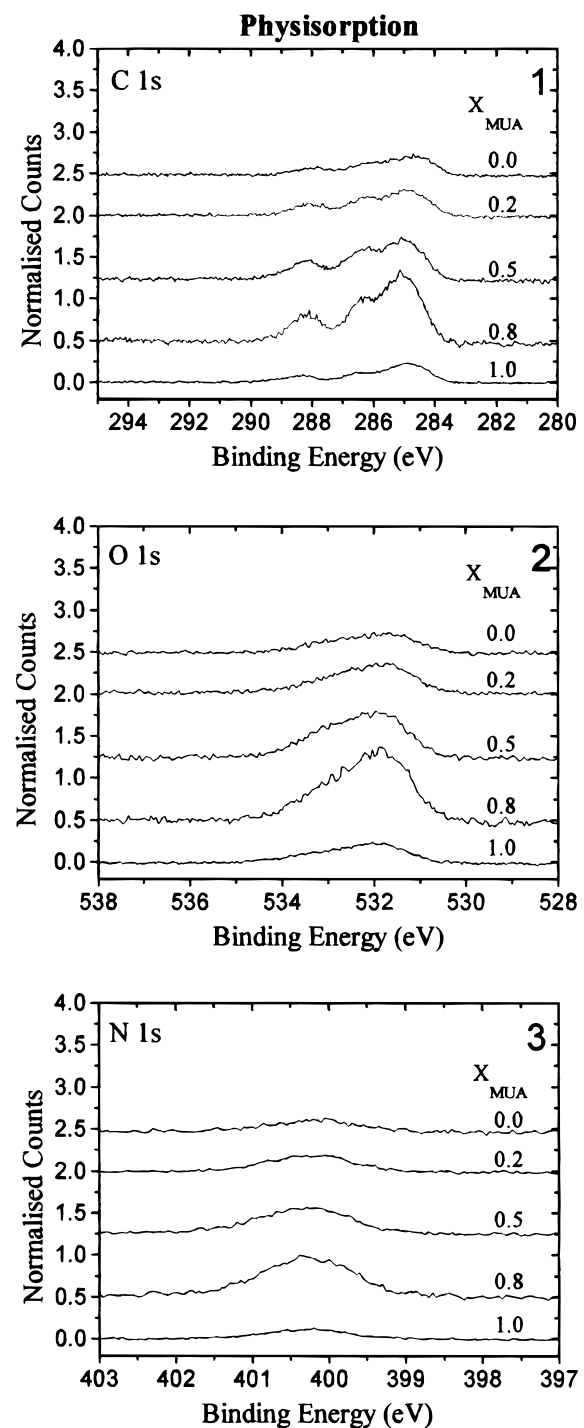

Figure 5. High-resolution XPS spectra of the $C 1 s, O$ ls, and $N$ 1s regi ons of a range of mixed SAMs containing GOX immobilized by (A) the covalent attachment method and (B) physisorption. X-ray power, $2.7 \mathrm{~kW}$ (spectra A1-3) and 1.4 kW (spectra B1-3); pass energy, $150 \mathrm{eV}$; TOA, $10^{\circ}$; and slit width, $0.8 \mathrm{~mm}$. $\mathrm{X}_{\mathrm{MUA}}$ is the molar fraction of MUA in the SAM. All the spectra were normal ized by di viding by the number of scans and the combined area of the Au $4 f 3 / 2$ and $4 f 5 / 2$ signals and were basel ine-corrected. Theintensities of spectra B1-3 weremultiplied by a factor of 2 . Some of thespectra were vertically displaced for ease of visual ization.

electrons across the SAM by quantum mechanical tunneling. The shape of the voltammograms obtained was indicative of a mechanism controlled by linear diffusion, ${ }^{42}$ implying that access via an array of widely spaced

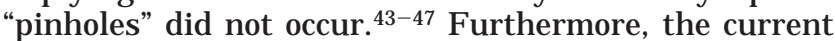
densities obtained with electrodes modified with SAMs were similar to those obtained with bare gold electrodes (Figure 4B), pointing out that electron transfer by tunneling across the thickness of the SAM did not occur either. ${ }^{48}$ As it is not possible to distinguish between membrane-type permeation and permeation via an array

(43) Greef, R.; Peat, R.; Peter, L. M.; Pletcher, D.; Robinson, J (Southampton Electrochemistry Group) Instrumental Methods in Electrochemistry; Ellis Horwood: Chichester, 1985; Chapter 6.

(44) Wightman, M. Anal. Chem. 1981, 53, 1125A.

(45) Savéant, J.-M. J . Electroanal. Chem. 1991, 301, 91.

(46) Chailapakul, O.; Crooks, R. M. Langmuir 1993, 9, 884.

(47) Sabatini, E.; Rubinstein, I. J . Phys. Chem. 1987, 91, 6663.

(48) The heterogeneous electron transfer rate constant decays exponentially with the distance (Marcus, R. A.; Sutin, N. Biochim. Biophys. Acta 1985, 811, 265).

(49) de Benedetto, G. O.; Malitesta, C.; Zambonin, C. G. J . Chem. Soc., Faraday Trans. 1994, 90, 1495. of closely spaced "pinholes", 45 these two paths cannot be ruled out. Additionally, permeation via a few large "defect sites" cannot be excluded.

Characterization of the Immobilization of GOX by XPS. The appearance of a N $1 \mathrm{~s} 1 / 2$ signal (centered at $400.3 \mathrm{eV}$ ) after the derivatization step, a new component band in the $C$ 1s $1 / 2$ region (centered at $286.6 \mathrm{eV}$ and assigned to carbon atoms linked to the sul fonate group of $\mathrm{NHSS}$ ), and in the $\mathrm{O} 1 \mathrm{~s} 1 / 2$ region (centered at $531.6 \mathrm{eV}$ and assigned to oxygen atoms in the sulfonate group) indicated that NHSS was present on the surface, al beit did not prove that the NHSS ester was formed (first step in Figure 1).

The presence of GOX immobilized on the surface of the SAMs could be confirmed by XPS. Figure 5 shows the XPS spectra obtained with samples containing GOX, immobilized either by thecovalent attachment method or by physisorption. The $\mathrm{C}$ 1s region showed three wellresolved peaks, in conformity with previously published spectra. ${ }^{49}$ The peak at $285.3 \mathrm{eV}$ was attributed to carbon atoms in a hydrocarbon-like environment, present in 
Table 1. Atomic Ratios from XPS Spectra of Mixed SAMs Containing GOX I mmobilized by Covalent Attachment and Physisorptiona

\begin{tabular}{ccc}
\hline $\mathrm{X}_{\text {MUA }}$ & $\mathrm{O} / \mathrm{C}$ & $\mathrm{N} / \mathrm{C}$ \\
\hline \multicolumn{3}{c}{ covalent attachment method } \\
0.8 & $0.86 \pm 0.12$ & $0.32 \pm 0.05$ \\
0.6 & $0.91 \pm 0.13$ & $0.38 \pm 0.05$ \\
0.4 & $0.89 \pm 0.13$ & $0.34 \pm 0.05$ \\
0.2 & $0.91 \pm 0.13$ & $0.31 \pm 0.04$ \\
& $0.88 \pm 0.13$ & $0.32 \pm 0.05$ \\
1.0 & physisorption method \\
0.8 & $0.86 \pm 0.12$ & $0.27 \pm 0.04$ \\
0.5 & $0.84 \pm 0.12$ & $0.33 \pm 0.05$ \\
0.2 & $0.82 \pm 0.12$ & $0.31 \pm 0.04$ \\
0.0 & $0.80 \pm 0.11$ & $0.29 \pm 0.04$ \\
act & $0.77 \pm 0.11$ & $0.33 \pm 0.05$
\end{tabular}

a Acquired at a take-off angle of $10^{\circ}(\mathrm{X}$-ray power, $2.7 \mathrm{~kW}$; pass energy, $150 \mathrm{eV}$; and slit width, $0.8 \mathrm{~mm}$ ). Standard deviation calculated from a systematic error of $10 \%$ in the value of the normalized areas.

amino acid side chains of the polypeptide backbone of the enzymeand in carbohydrateresidues of its polysaccharide shell. The peak at $286.8 \mathrm{eV}$ was attributed to carbon linked to oxygen by a single bond, present in the polysaccharide shell and in amino acid side chains. The highest binding energy signal (288.7 eV) was attributed to carbon atoms linked to oxygen via a double bond, present in the amide groups of the polypeptide backbone, in some amino acid side chains and in $\mathrm{N}$-acetylglucosamine residues of the polysaccharide shell. The $\mathrm{O}$ is signal contained two components: (i) a signal at $533.3 \mathrm{eV}$, assigned to oxygen atoms in $\mathrm{C}=\mathrm{O}$ groups, present in both the polypeptide backbone (amide bond and amino acid side chains) and in the $\mathrm{N}$-acetylglucosamine residues and (ii) a signal at $532.1 \mathrm{eV}$, assigned tooxygen atoms in $\mathrm{C}-\mathrm{O}$ groups, present in ami noacid sidechains and carbohydrateresidues. The $\mathrm{N}$ 1s peak at $400.1 \mathrm{eV}$ was assigned to nitrogen atoms present in theami debonds in thepolypeptidechain, amino acid side chains, and $\mathrm{N}$-acetylglucosamine residues.

When the enzyme was immobilized by covalent attachment, theamount of enzymeon thesurface increased with increasing $\mathrm{C} 7$ content of the mixed MU A/C 7 SAM, rather than increasing with the percentage of carboxylic groups on the surface (Figure 5A1-3). This result suggested the occurrence of physisorption in parallel with covalent attachment. I ndeed, in an independent experiment, GOX was immobilized by physisorption onto all of the mixed SAMs studied (Figure 5B1-3). In this case, the amount of physisorbed GOX showed theoppositetrend, increasing with the hydrophilicity of the SAM, before reaching a maximum value for $X_{M \cup A}=0.8$ and decreasing for $X_{M \cup A}$ $=1.0$. A comparison of the areas of the $\mathrm{N}$ 1s peaks shows that the immobilization yiel d for the covalent attachment method was significantly higher than the physisorption yield only when $\mathrm{X}_{\mathrm{MUA}}=0.2$.

The variation of the O/C and N/C atomicratios with the composition of the SAM, in samples with immobilized GOX, was studied (Table 1). In both immobilization methods, these atomic ratios did not vary significantly with the composition of thesurface onto which theenzyme was immobilized. The atomic ratios for the two types of immobilization were not significantly different, and the ratios obtained at a TOA of $90^{\circ}$ (data not shown) werealso not significantly different from those obtained at $10^{\circ}$. The XPS atomic ratios were compared with atomic ratios expected for the enzyme molecules, calculated from the amino acid content of the enzyme ${ }^{50}$ and from the average number of carbohydrate residues per mole of enzyme. ${ }^{51}$ TheXPS O/C ratios were different from that expected for both the whole enzyme and the proteic core $(0.35)$ but were similar to that expected for the polysaccharide shell $(0.82 \pm 0.19)$, indicating that carbohydrate units existed at the topmost part of the immobilized enzyme molecule. The XPS N/C ratio was similar to the value expected for both the whole enzyme and for the proteic core (0.29) and morethan 1 or der of magnitudehigher than that expected for the polysaccharide shell $(0.020 \pm 0.005)$, indicating that the proteiccore predominated in thesampling depth. The reason for the lack of agreement between the information extracted from the $\mathrm{N} / \mathrm{C}$ ratios and that extracted from the $\mathrm{O} / \mathrm{C}$ ratios is not clear. ${ }^{52}$

At a TOA of $10^{\circ}$, a continuous overlayer of GOX on the SAM, with the molecule in any orientation, would completely attenuate the Au $4 \mathrm{f}$ signal. At a TOA of $90^{\circ}$, only a continuous layer of enzyme molecules oriented according to their largest axis ("standing up") would completely attenuate the Au $4 \mathrm{f}$ signal (Figure 1). ${ }^{53}$ The fact that a signal from the gold underlayer was present at TOAs of $10^{\circ}$ indicated that either the enzymelayer was discontinuous or that the enzyme dimensions were lower than in the native state (implying that a major conformational change had occurred). The occurrence of the Au $4 \mathrm{f}$ signal also at a TOA of $90^{\circ}$ indicated that the enzyme layer was discontinuous, theenzymemolecules were "Iying down" on the SAM (Figure 1), or the enzyme dimensions were lower than those in the native state. Because immobilized enzyme was detected by FTI R-ATR, enzyme activity was detected in all the samples tested (as will be shown later), and AF M studies of GOX immobilized onto el ectrode surfaces reveal ed an irregular coating of enzyme molecules, 8 it is highly likely that the enzyme does not cover all the surface.

FTIR Characterization of Glucose Oxidase I mmobilized onto SAMs. The study of the conformational state of GOX immobilized onto two microenvironments of different hydrophilic character was carried out. The FTIR-ATR analysis allowed the acquisition of spectra of immobilized enzyme in an aqueous medium and allowed an appropriate compari son with the FTIR spectrum of its native conformation in solution. The enzyme was immobilized by the NHSS/EDAC method onto MUA/C7 SAMs or by physisor ption onto C 7SAMs, i.e., immobilized onto microenvironments of opposite hydrophilic character. TheFTIR-ATR spectra obtained areshown in Figure 6 , and peak maxima and peak intensities are given in Table 2. In both types of immobilization, the amide I and amide II bands were shifted to lower frequencies and

(50) Amino acid sequence obtained from the Brookhaven Protein Data Bank.

(51) GOX is a glycoprotein, possessing a polysaccharide shell. It is thought that the polysaccharide partially surrounds the proteic core (Degani, Y.; Heller, A. J . Phys. Chem. 1987, 91, 1285). I ts carbohydrate content was estimated from data in: Pazur, J . H.; Kleppe, K.; Cepure A. Arch. Biochem. Biophys. 1965, 111, 351. Hayashi, S.; Nakamura, S. Biochim. Biophys. Acta 1976, 438, 37. Nakamura, S.; Hayashi, S.; Hasumi, H. In Flavins and Flavoproteins; Singer, T. P., Ed.; Elsevier: Amsterdam, 1976; p 691. Nakamura, S.; Hayashi, S.; Koga, K. Biochim. Biophys. Acta 1976, 445, 294.

(52) It is not caused by differences in the penetration depth of the $\mathrm{O}$ is and $\mathrm{N}$ is electrons, because they are not significantly different: the penetration depth at a TOA of $10^{\circ}$ is $0.3-0.6 \mathrm{~nm}$ for $\mathrm{O}$ 1s electrons and $0.3-0.8 \mathrm{~nm}$ for $\mathrm{N}$ 1s electrons (from data in: Seah, M.P. In Practica SurfaceAnal ysis by Auger and X-ray Photoel ectron Spectroscopy; Briggs, D., Seah, M. P., E ds.; J ohn Wiley \& Sons: Chichester, 1983; Chapter. $5, \mathrm{p}$ 186).

(53) The sampling depth of the $A u 4 f$ signal is $1.1-1.6 \mathrm{~nm}$ at a TOA of $10^{\circ}$ and $6.3-9.0 \mathrm{~nm}$ at $90^{\circ}$ (from data in: Seah, M. P. In Practical SurfaceAnalysis by Auger and X-ray Photoel ectron Spectroscopy; Briggs, D., Seah, M. P., Eds.; J ohn Wiley \& Sons: Chichester, 1983; Chapter 5, p 186). GOX dimensions ${ }^{5}$ are shown in Figure 1 . The ellipsometric thickness of a pure MUASAM is 1.4-1.7 nm (Evans, S. D.; UIman, A. Goppert-Berarducci, K. E .; Gerenser, L. J .J . Am. Chem. Soc. 1991, 113, 5866) and of a pure C7SAM is $0.6-0.7 \mathrm{~nm}^{13}$ 


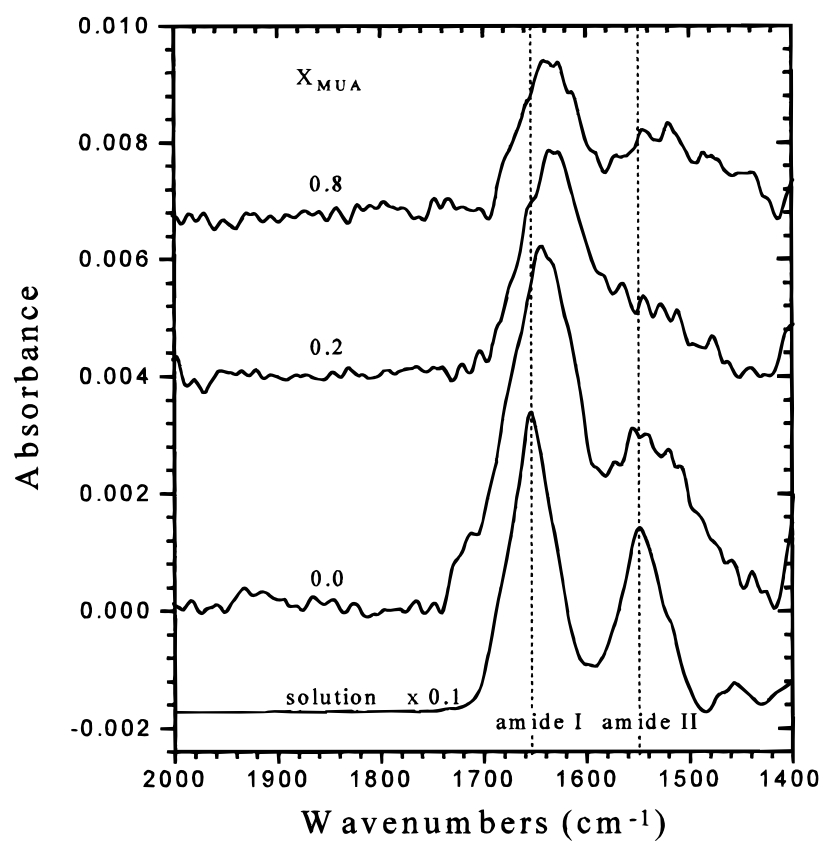

Figure 6. FTIR-ATR spectra of GOX immobilized onto mixed MUA/C7 SAMs of varying molar fractions of MUA ( $\left.X_{M \cup A}\right)$, acquired in $0.1 \mathrm{M}$ sodium phosphate buffer, at $\mathrm{pH}$ 7.0. F or $\mathrm{X}_{\mathrm{MUA}}$ $=0.2$ and 0.8 , the enzyme was immobilized by the covalent attachment method; for $\mathrm{X}_{\mathrm{MUA}}=0.0$ (C7SAM), GOX was immobilized by physi sorption. Thespectrum of GOX in solution was acquired in transmi ssion mode, in theabovebuffer solution. The intensity of the spectrum of the enzyme in solution was multiplied by a factor of 0.1. The dotted lines are centered on the position of theamidel and amidell maxima of thespectrum of the enzyme in solution (1654 and $1549 \mathrm{~cm}^{-1}$, respectively). The spectra were baseline-corrected and vertically displaced for ease of visualization.

Table 2. Peak Maxima and Full Widths at Half-Height (fwhh) of Amide I and Amide II Bands, Their Intensity Ratios, and the Normalized Intensity of the Amide II Band in FTIR Spectra of GOX I mmobilized onto Different SAMs and in Solution

\begin{tabular}{|c|c|c|c|c|c|c|}
\hline \multirow[b]{2}{*}{ spectrum } & \multicolumn{2}{|c|}{ amide $\left(\mathrm{cm}^{-1}\right)$} & \multicolumn{2}{|c|}{ amide II $\left(\mathrm{cm}^{-1}\right)$} & \multirow[b]{2}{*}{$I / / I^{a}$} & \multirow[b]{2}{*}{$\mathrm{I}_{1550^{\mathrm{b}}}$} \\
\hline & $\begin{array}{c}\text { peak } \\
\text { max } \\
\left(\mathrm{cm}^{-1}\right)\end{array}$ & $\begin{array}{l}\text { fwhh } \\
\left(\mathrm{cm}^{-1}\right)\end{array}$ & $\begin{array}{c}\text { peak } \\
\text { max } \\
\left(\mathrm{cm}^{-1}\right)\end{array}$ & $\begin{array}{l}\text { fwhh } \\
\left(\mathrm{cm}^{-1}\right)\end{array}$ & & \\
\hline olut & 1654 & 45 & 1549 & 45 & 1.6 & C \\
\hline$=0.8^{\mathrm{d}}$ & 1636 & 60 & 1521 & 108 & 1 & 0.32 \\
\hline$X_{\text {MUA }}=0.2^{d}$ & 1632 & 66 & 1538 & 84 & 2.7 & 0.28 \\
\hline$X_{\text {MUA }}=0.0^{e}$ & 1643 & 69 & 1538 & 102 & 2.0 & 0.35 \\
\hline
\end{tabular}

a Ratio of the maximum intensity of the amidel band to that of the amide II band. ${ }^{b}$ N ormalized intensity of the amide II band at $1550 \mathrm{~cm}^{-1}$. ${ }^{\mathrm{c}}$ Not applicable. ${ }^{\mathrm{d}}$ Covalent attachment. e Physisorption.

showed fwhh values that were above that found for GOX in its nativestate (i.e., in solution). Theamidel band was shifted between 9 and $22 \mathrm{~cm}^{-1}$; the smallest shift occurred for the enzyme immobilized onto the C7SAM, and the largest occurred for theenzymeimmobilized on themixed MUA/C7 SAM with $X_{\text {MUA }}=0.2$. The amide II band was alsoshifted tolower frequencies by $11-28 \mathrm{~cm}^{-1}$. Theshifts in the maximum of the amide I band did not decrease regularly with an increase in the hydrophobicity of the surface. The fwhh of the amide I band increased with an increasein thehydrophobicity of thesurface. Theincreased bandwidths indicate that the amide groups of the immobilized enzyme experience a wider range of microen-

(54) Harrick, N. J . Internal Reflection Spectroscopy; Interscience Publishers: New York, 1967; Chapter 2. vironments than when they belong toan enzyme molecule in solution, in its native conformation, suggesting that the presence of the surface alters the enzyme's conformation.

When comparing ATR spectra of thin films with transmission spectra of bulk samples, differences in band intensity can occur because of the different sampling modes. Thus, in the ATR mode, the penetration depth of the evanescent wave is directly proportional to the wavelength of the radiation. ${ }^{54}$ In addition, because of the presence of a gold layer on the ATR crystal, the intensity of the electric field of p-polarized light is about 1 order of magnitude greater than that of s-polarized light. ${ }^{55}$ This effectively introduces a surface selection rule in which only transiti on moments with a component perpendicular to the surface will interact with the incoming radiation. The difference in penetration depth at the peak positions of the amide I and amide II bands is expected to increase theamidel/amide II intensity ratio by a factor of 1.1. The amidel/amide II ratios obtained were al ways above this value (Table 2). Because the direction of the dipole transition moment for amidel forms an angle of $15^{\circ}-25^{\circ}$ in relation to the direction of the $\mathrm{C}=\mathrm{O}$ bond in the plane of the amide group whereas for the amidell this angle is $73^{\circ}, 56$ the other two factors would be important if we were in the presence of a population of immobilized, oriented enzyme molecules. However, the occurrence of a population of enzyme molecules immobilized in a same orientation is unlikely because physisorbed enzyme molecules occur with both methods of immobilization and enzyme molecules physisorbed onto heterogeneous, disordered surfaces are expected to have a broad orientation distribution. Thus, it can be said that the amide I/amide II intensity ratio increased upon immobilization (Table 2), an indication that conformational changes have occurred. ${ }^{57}$

After suitablenormalization of theintensity of theFTIRATR spectrum, the amide II band intensity at $1550 \mathrm{~cm}^{-1}$ gives an indication of the amount of protein present, because it varies linearly with the amount of adsorbed protein. ${ }^{58}$ The intensities of the amide II bands at 1550 $\mathrm{cm}^{-1}$ of GOX immobilized onto the different SAMs were similar (Table 2), indicating that the amounts of enzyme immobilized are comparable, with the highest values corresponding to immobilization by physisorption onto the C7SAM and by covalent attachment onto the MUA/ C7 SAM with the highest MUA molar fraction (0.8).

The original amidel envel ope of theenzymein solution and of enzyme immobilized onto SAMs was deconvoluted into its component bands by a combination of second derivative spectroscopy, FSD, and curve-fitting. The relative areas of the bands attributed to $\alpha$ helix, $\beta$ sheet, turns, and unor dered segments were used as an estimate

(55) Cheng, Y.; Boden, N.; Bushby, R. J .; Clarkson, S.; Evans, S. D.; Knowles, P. F.; Marsh, A.; Miles, R. E. Langmuir 1998, 14, 839.

(56) Krimm, S.; Bandekar, J . Adv. Protein Chem. 1986, 38, 181

(57) Lenk, T. J .; Ratner, B. D.; Gendreau, R. M.; Chittur, K. K. J Biomed. Mater. Res. 1989, 23, 549. J akobsen, R. J .; Wasacz, F. M. Appl Spectrosc. 1990, 44, 1478

(58) Fink, D. J .; Hutson, T. B.; Chittur, K. K.; Gendreau, R. M. Anal. Biochem. 1987, 165, 147.

(59) The percentage of el ements of secondary structure in GOX was calculated with Kabsch and Sander's algorithm (Kabsch, W.; Sander, S. Biopol ymers 1983, 22, 2577) from data in protein databases: (i) SwissProt Database $-27 \% \alpha$ helix, 20\% $\beta$ sheet, and 28\% turns; and (ii) Brookhaven Protein Data Bank - 20\% $\alpha$ helix and $17 \% \beta$ sheet.

(60) On the basis of assignments by: Byler and Susi. ${ }^{35}$ Surewicz, W K.; Leddy, J . . .; Mantsch, H. H. Biochemistry 1990, 29, 810. Surewicz W. K.; Mantsch, H. H.; Chapman, D. Biochemistry 1993, 32, 389. Kumosinski, T. F.; Unruh, J .J . ACS Symp. Ser. 1994, 576, 71. Middaugh, C. R.; Mach, H.; Ryan, J . A.; Sanyal, G.; Volkin, D. B. Methods Mol . Biol . 1995, 40, 137. 
Table 3. Percentage of Elements of Secondary Structure of GOX I mmobilized onto Mixed MUA/C7 SAMs or in Solution ${ }^{a}$

\begin{tabular}{ccccc}
\hline & $\begin{array}{c}\alpha \text { helix } \\
(\%)\end{array}$ & $\begin{array}{c}\beta \text { sheet } \\
(\%)\end{array}$ & $\begin{array}{c}\text { turns } \\
(\%)\end{array}$ & $\begin{array}{c}\text { unordered } \\
(\%)\end{array}$ \\
\hline solution & 25 & 23 & 33 & 15 \\
$\mathrm{X}_{\text {MUA }}=0.8^{b}$ & 19 & 29 & 7 & 31 \\
$\mathrm{X}_{\text {MUA }}=0.2^{\mathrm{b}}$ & 21 & 27 & 2 & 31 \\
$\mathrm{X}_{\text {MUA }}=0.0^{c}$ & $\mathrm{~d}$ & 24 & 22 & $\mathrm{~d}$
\end{tabular}

a Determined by curve-fitting of the amidel infrared band. The band assignments were: $\alpha$ helix, $1654-1657 \mathrm{~cm}^{-1} ; \beta$ sheet, 1670 $1678,1635 \mathrm{~cm}^{-1}$ and $1625-1627 \mathrm{~cm}^{-1}$; turns, $1693,1681-1688$, and $1667 \mathrm{~cm}^{-1}$; and unordered segments, $1638-1645 \mathrm{~cm}^{-1}$. 60 The undetermined structure is associated to unassigned single bands occurring at $1613-1616$ and $1602-1605 \mathrm{~cm}^{-1}$, related to unfolded aggregated molecules or $\beta$ structure and to side chains of amino acids, respectively. ${ }^{60} \mathrm{~b} / \mathrm{mmobilization}$ by covalent attachment. c I mmobilization by physisorption. ${ }^{d}$ It was not possible to resolve the contribution of $\alpha$ helices from that of unordered segments. The percentage of $\alpha$ helix + unordered segments was $41 \%$.

of the percentage of the elements of secondary structure in the enzyme structure. An estimate of the enzyme's content in elements of secondary structure was obtained from analysis of databases containing its three-dimensional structure, as determined by X-ray diffraction ${ }^{59}$ (Table 3).

The quantitative results of the FTIR analysis for the enzyme in solution agreed with the data obtained from the protein databases, apart from a slight over estimation of the percentages of $\beta$ sheet and turns. The quantitative analysis of the secondary structure of GOX immobilized ontothedifferent SAMs and in solution (Table3), revealed that the percentages of $\alpha$ hel ix and turns decreased upon immobilization, while the percentages of $\beta$ sheet and unordered segments increased. As the hydrophilicity of the microenvironment in which GOX was immobilized was increased, the percentage of $\beta$ sheet al so increased. ${ }^{61}$

Activity of the I mmobilized GOX. The activity of GOX immobilized onto two different mi croenvironments (hydrophobic C7SAM or hydrophilicmixed MUA/C 7SAM of $X_{\text {MUA }}=0.8$ ) by two different immobilization methods (physisorption or covalent attachment method, respectively) was studied by cyclic voltammetry. When GOX was immobilized onto the two sets of SAM-modified gold electrodes, the cyclic voltammograms of HMFc showed higher currents after the addition of glucose, revealing that a population of active, immobilized enzymemolecules existed on the surface of the SAMs (Figure 7). Because $\mathrm{HMF} \mathrm{c}$ was added to the test sol ution and was detected by the gold layer underneath the SAM and enzyme layers, an adequate comparison of the total enzyme activity in thetwo differ ent sets of el ectrodes containing immobilized GOX would require these two different sets of electrodes to detect GOX activity with similar sensitivity. Such sensitivity was evaluated by recording the response of each of the two sets of electrodes after addition to thetest solution of a known amount of GOX, in the presence of HMF c and glucose. Beforehand, the effect of the layer of immobilized enzyme on the reversibility of the oxidation of HMF cwas evaluated by comparing thevol tammograms acquired with SAM-only modified electrodes with those acquired with SAM-modified el ectrodes with immobilized GOX (in the absence of glucose). The voltammograms obtained with thetwo sets of SAM-only modified el ectrodes

(61) For other proteins, gain in the amount of $\beta$ sheet, sometimes accompanied by gain in the amount of unordered segments and loss in the amount of $\alpha$ helix, as a consequence of their immobilization, has been reported (for example, see: Castillo, E.J .; Koenig, J . L.; Anderson, J. M.; Lo, J . Biomaterials 1984, 5, 319. Lenk et al. ${ }^{57}$ ).

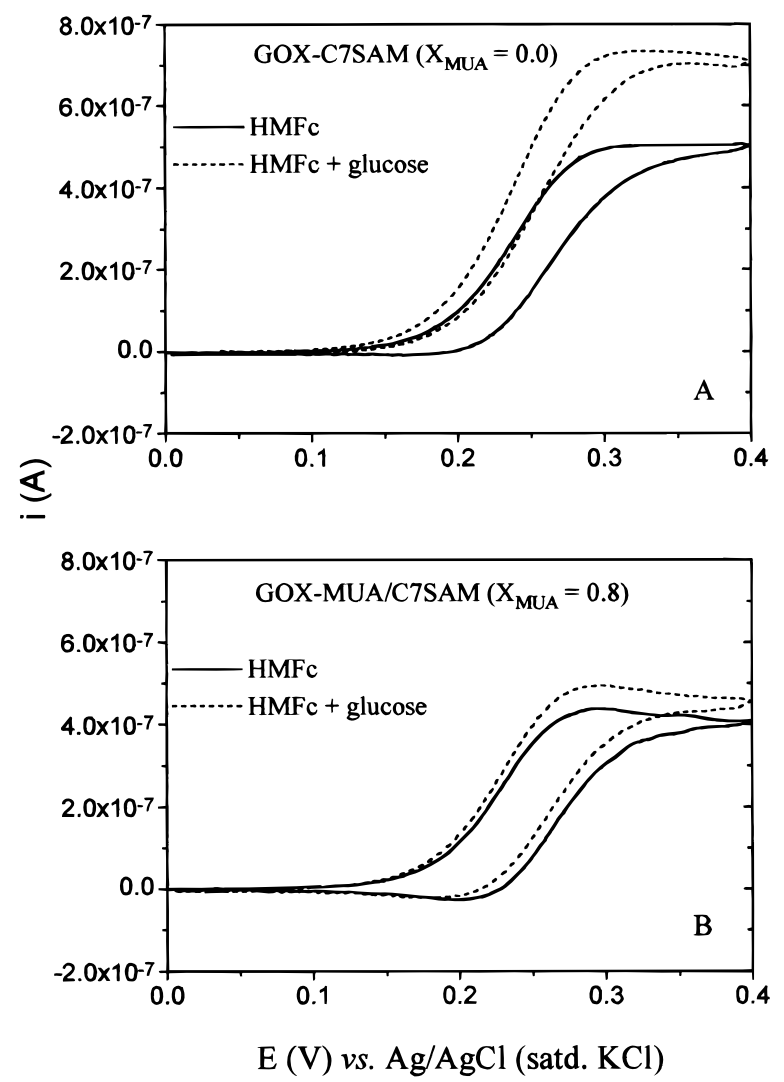

Figure 7. Cyclicvoltammograms representative of theactivity test of immobilized GOX in the case of immobilization by $(A)$ physisorption to electrodes modified with C7SAMs and (B) covalent attachment to electrodes modified with mixed MUA/ C7 SAMs $\left(X_{\text {MUA }}=0.8\right)$. The cyclic voltammograms are representative of those obtained with a $50 \mu \mathrm{M}$ HMFc solution in sodium phosphate/ $\mathrm{NaCl}$ buffer solution of I $=0.1 \mathrm{M}$ and $\mathrm{pH}=$ 8.0, before (full lines) and after (dotted lines) addition of glucose to a concentration of $50 \mathrm{mM}$ (el ectrode area, $0.26 \mathrm{~cm}^{2} ; \mathrm{T}, 25^{\circ} \mathrm{C}$; scan rate, $1 \mathrm{mV} / \mathrm{s}$ ).

(Figure 8, full lines) showed different degrees of reversibility. In the case of electrodes with immobilized GOX, theoxidation of HMFcbyC7SAM-modified el ectrodes with GOX immobi lized by physi sor ption was markedly affected by the presence of the immobilized enzyme layer ( $F$ igure 8, dotted lines). I n contrast, thepresence of theimmobilized enzyme layer on the mixed MUA/C7 SAM-modified electrodes did not affect the oxidation of HMFc. In view of this effect of the immobilized enzyme layer, the sensitivity to detection of GOX activity referred above was estimated from the response of SAM-modified electrodes with immobilized GOX, after addition of a known amount of GOX to the test solution ${ }^{62}$ (rather than from a similar assay performed with SAM-only modified electrodes). The catalytic enhancement of the current ( $i_{\text {cat }}$, the difference between the current in the presence and absence of catalysis, at a potential past theoxidation peak) was used to characterize the activity of GOX.

The sensitivity to detection of GOX in solution, for C7SAM-modified el ectrodes with physisor bed GOX ( $i_{\text {cat }}=$ $98 \pm 20 \mathrm{nA}$ ), was higher than the sensitivity of electrodes

(62) The amount of GOX added to the test solution was equivalent to a randomly packed monolayer of enzyme molecules on the projected area of the electrode, estimated from the enzyme's projected area (58 $\mathrm{nm}^{2}$, calculated from theStokes radius ${ }^{5}$ ), considering that approximately only $60 \%$ of the substrate's area can be covered with GOX molecules (Bourdillon, C.; Demaille, C.; Gueris, J .; Moiroux, J .; Savéant, J .-M.J . Am. Chem. Soc. 1993, 115, 12264). The maximum number of moles of randomly packed GOX molecules per square centimeter is then $1.7 \times$ $10^{-12}$. 

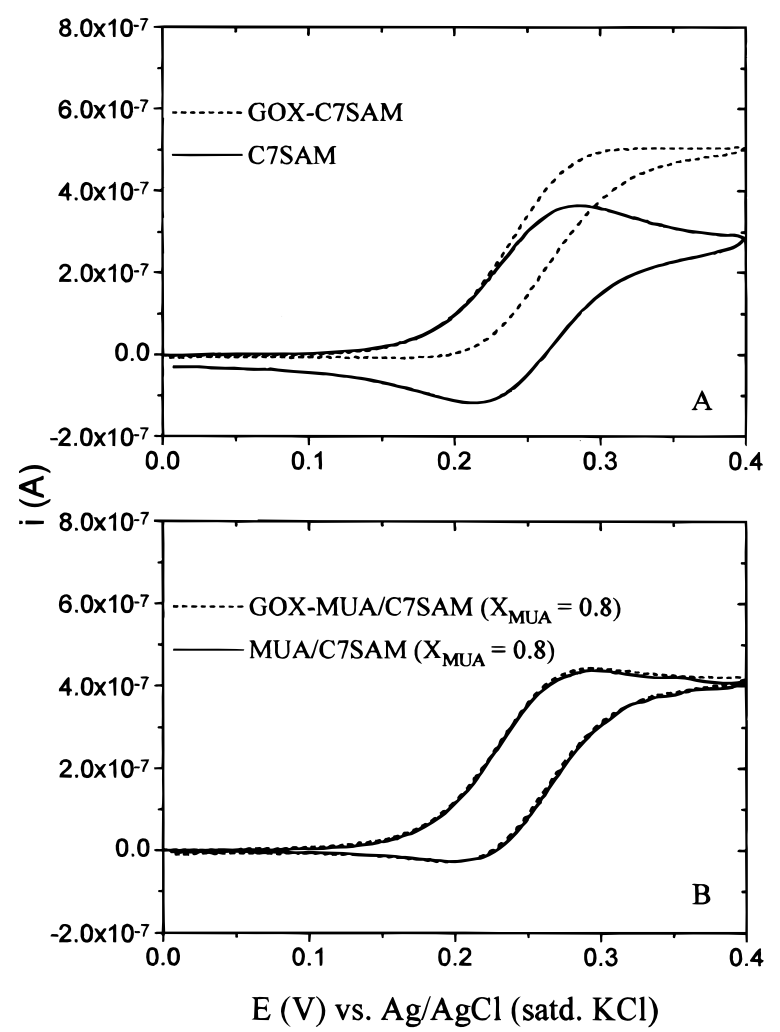

Figure 8. Cyclic voltammograms representative of the effect of the presence of immobilized GOX in the oxidation/reduction of $\mathrm{HMFc}$, in the case of immobilization by (A) physisorption to electrodes modified with C7SAM s and (B) covalent attachment to electrodes modified with mixed MUA/C7 SAMs $\left(X_{\text {MUA }}=0.8\right)$. Thecyclicvoltammograms are representativeof thoseobtained with a $50 \mu \mathrm{M} \mathrm{HMF}$ csol ution in a sodium phosphate/ $\mathrm{NaCl}$ buffer solution of $\mathrm{I}=0.1 \mathrm{M}$ and $\mathrm{pH}=8.0$, in the absence of glucose, at a SAM-modified electrode without (full lines) and with immobilized GOX (dotted lines) (el ectrodearea, $0.26 \mathrm{~cm}^{2} ; \mathrm{T}, 25$ ${ }^{\circ} \mathrm{C}$; scan rate, $1 \mathrm{mV} / \mathrm{s}$ ).

with GOX i mmobilized by the covalent attachment method onto electrodes modified with a mixed MUA/C7 SAM of $X_{\text {MUA }}=0.8\left(i_{\text {cat }}=75 \pm 20 \mathrm{nA}\right)$, by a factor of $1.3 \pm 0.4$. The activity of GOX immobilized by physisorption onto electrodes modified with C7SAM ( $i_{\text {cat }}=224 \pm 20 \mathrm{nA}$ ) was al so higher than the activity of GOX immobilized by the coval ent attachment method onto el ectrodes modified with the mixed MUA/C7 SAM ( $i_{\text {cat }}=53 \pm 20 \mathrm{nA}$ ), by a factor of $4.2 \pm 1.6$. Theseresults indicatethat theenzymeactivity present in the case of immobilization onto the C7SAM was $3.2 \pm 1.6$ times higher than the activity present in the case of immobilization onto the MUA/C7 SAM with $\mathrm{X}_{\mathrm{MUA}}=0.8$. Because the amount of enzyme immobilized onto the C7SAM, expressed as the normalized intensity of the amide II band (Table 2), was similar to that immobilized onto the mixed MUA/C7 SAM, the result obtained indicated that the specific activity of GOX immobilized onto the hydrophobic microenvironment (C7SAM surface) was higher than that of GOX immobilized ontothe hydrophilic microenvironment (mixed MUA/C7 SAM [X $\left.X_{\text {MUA }}=0.8\right]$ surface).

Thelack of activity of GOX when immobilized onto the hydrophilic microenvironment can be correlated with the dramatic decrease in the percentage of turns and the slight increase in the percentage of $\beta$ sheet in thestructure of the enzyme, when compared to the respective percentages of the enzymeeither in solution or when immobilized onto the hydrophobicSAM (Table3). No correlation could be established with the percentage of $\alpha$ helices or unordered segments, because data for the percentages of these elements for the enzyme immobilized onto the hydrophobic SAM could not be obtained (Table 3).

\section{Conclusions}

Mixed SAMs showing molar fractions of MUA and C7 which reproduced those of the solutions from which they were formed were obtained. The hydrophilicity of the surface of theSAM was a function of the ratio of these two molecules. Themolecules werenot macroscopically phase segregated, except when one species of mol ecules dominated the composition of the mixed SAM. Indication of the occurrence of "defect sites" in our SAMs was found electrochemically. Oxidation of HM F c by gold electrodes modified with these SAMs occurred in a quasireversible mode.

The derivatization of the mixed MUA/C7 SAMs with NHSS was confirmed by XPS. Glucose oxidase could be immobilized onto these mixed SAMs following this derivatization. The presence of the enzyme was detected by both XPS and FTIR spectroscopy. TheXPS study indicated that physisorption of the enzyme also occurred during the immobilization by the covalent attachment method. Thesemiquantitativeanalysis of theF TIR data indicated that the yields of immobilization were not significantly different.

The occurrence of conformational changes upon immobilization was revealed by FTIR spectroscopy. The percentages of $\alpha$ helix and turns decreased upon immobilization, while the percentages of $\beta$ sheet and unordered segments increased. In addition, the percentage of $\beta$ sheet increased with an increase in thehydrophilicity of the microenvironment, suggesting that the conformational changes were dependent on the hydrophilic character of the microenvironment.

Enzymatic activity could be detected after immobilization of glucose oxidase onto a hydrophilic microenvironment by the covalent attachment method and immobilization onto a hydrophobic microenvironment by physisorption. The magnitude of the responses, the relative amounts of immobilized enzyme, and the relative sensitivities of theel ectrodes, indicated that thespecificactivity of GOX immobilized onto the hydrophobic microenvironment was higher than that of GOX immobilized onto the hydrophilic microenvironment.

Acknowledgment. The authors thank Dr. Rong Luo (Department of Mining and Mineral Engineering, University of Leeds) for hel $p$ with theel ectrochemical studies, and the referees for their suggestions. A.J .G. was on leave from the Departamento de Bioquímica, Faculdade de CiênciaseTecnologia, UniversidadedeCoimbra, Portugal. He thanks J .N.I.C.T. (Portugal) for personal financial support (Praxis XXI program).

LA980974T 